\title{
Report 3: Cost-Effective Reciprocating Engine Emissions Control and Monitoring for E\&P Field and Gathering Engines
}

\author{
Technical Progress Report \\ DOE Award DE-FC26-02NT15464 \\ Work completed: July 31, 2003 - September 30, 2003 \\ Author \\ Kirby S. Chapman, Ph.D., Kansas State University \\ Submitted by \\ Kansas State University \\ National Gas Machinery Laboratory \\ 245 Levee Drive \\ Manhattan, KS 66502
}

Significant Assistance Provided by

Coerr Environmental Corporation 400 Silver Cedar Court, Suite 240

Chapel Hill, NC 27514

Energy and Environmental Analysis 1655 N Fort Meyer Drive, Suite 60

Arlington, VA 22209

December, 2003 


\section{Disclaimer}

This report was prepared as an account of work sponsored by an agency of the United States Government. Neither the United States Government nor any agency thereof, nor any of their employees, makes any warranty, express or implied, or assumes any legal liability or responsibility for the accuracy, completeness, or usefulness of any information, apparatus, product, or process disclosed, or represents that is use would not infringe privately owned rights. Reference herein to any specific commercial product, process, or service by trade name, trademark, manufacturer, or otherwise does not necessarily constitute or imply its endorsement, recommendation, or favoring by the United States Government or any agency thereof. The views and opinions of authors expressed herein do not necessarily state or reflect those of the United States Government or any agency thereof. 


\section{Abstract}

During the third reporting period, the project team continued to focus on identifying promising technologies that can then be used to monitor and control emissions from E\&P engines. These technologies include control and monitoring technologies and in most cases can be used to monitor engine performance as well as control and monitor engine emissions.

The engine frequency distribution used in the E\&P industry was significantly enhanced, and now shows the most prevalent engines used in the industry. The most prevalent four stroke cycle engines are the Waukesha and Caterpillar engines, while the most prevalent two-stroke cycle engine is the Ajax. 


\section{Table of Contents}

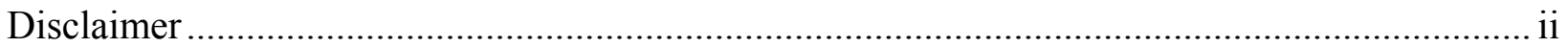

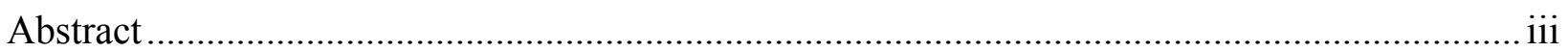

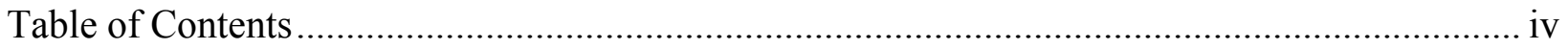

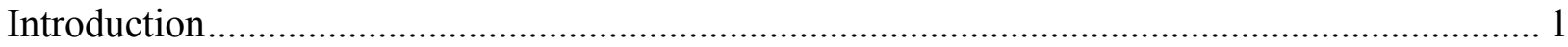

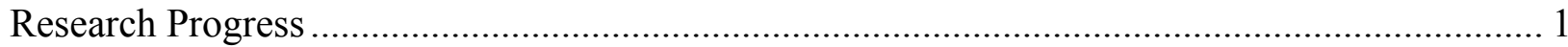

Task 2: $\quad$ Develop a database of existing E\&P engine inventory................................... 1

Task 3: Identify and assess commercial and emerging control and monitoring technologies 9

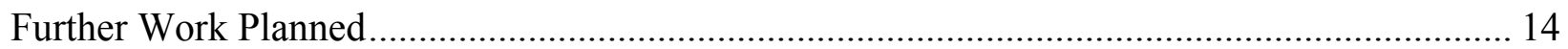

Task 2: Develop a Database of Existing E\&P Engine Inventory ...................................... 14

Task 3: Assess Control and Monitoring Technologies ................................................... 14

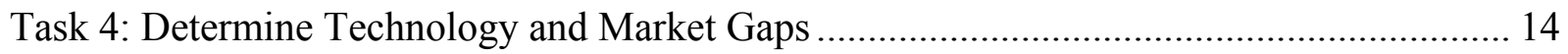

Task 5: Conduct Controlled Tests to Evaluate Promising Technologies .............................. 14

Task 6: Determine on-engine control system and sensor requirements for remote emissions

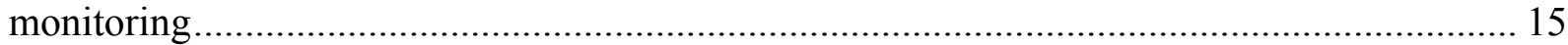

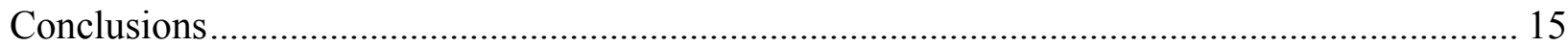




\section{Introduction}

The objective of this project is to identify, develop, test, and commercialize emissions control and monitoring technologies that can be implemented by exploration and production (E\&P) operators to significantly lower their cost of environmental compliance and expedite project permitting. The project team will take considerable advantage of the emissions control research and development efforts and practices that have been underway in the gas pipeline industry for the last 12 years. These efforts and practices are expected to closely interface with the E\&P industry to develop cost-effective options that apply to widely-used field and gathering engines, and which can be readily commercialized.

The project is separated into two phases. Phase 1 work establishes an E\&P industry liaison group, develops a frequency distribution of installed E\&P field engines, and identifies and assesses commercially available and emerging engine emissions control and monitoring technologies. Current and expected E\&P engine emissions and monitoring requirements will be reviewed, and priority technologies will be identified for further development. The identified promising technologies will be tested on a laboratory engine to confirm their generic viability. In addition, during Phase 2 a full-scale field test of prototype emissions controls will be conducted on at least ten representative field engine models with challenging emissions profiles. Emissions monitoring systems that are integrated with existing controls packages will be developed. Technology transfer/commercialization is expected to be implemented through compressor fleet leasing operators, engine component suppliers, the industry liaison group, and the Petroleum Technology Transfer Council.

\section{Research Progress}

Primary effort during this reporting period continues to focus on Tasks 2 and 3 . The efforts in Task 2 developed a more comprehensive list of engines used in the existing E\&P engine fleet and the efforts in Task 3 focused on the characterizing existing and emerging emission control and monitoring technologies.

\section{Task 2: Develop a database of existing E\&P engine inventory}

During the reporting period of July 1, 2003 to September 30, 2003, Coerr Environmental continued to develop the database of E\&P stationary gas field and gathering engines. In addition to engine population information gathered previously, 267 engines at stations with newly permitted units in nine western states were added to the frequency distribution database, and 250 more gathering engines were added.

In response to the directive of the project steering committee, we have focused on developing frequency statistics for engine models used in natural gas gathering and have characterized the engines by horsepower and air fuel ratio type. There are currently 4,729 engines in the project database. Table 1 shows the frequency of engine models in the database with horsepower, air fuel ratio, and cycle type. The manufacturer/model most represented in the database is the Waukesha H 24 GL followed by the Caterpillar G 3408 TA. The first 20 engine types on the table represent $85 \%$ of the entire database. The most prevalent two stroke cycle engine is the Ajax. Table 2 shows the sources of the engine information. 
Table 1. Gathering Engines in the DOE Project Database Sorted by Frequency

\begin{tabular}{|c|c|c|c|c|c|c|}
\hline Manufacturer & Model & $\begin{array}{c}\text { Air Fuel } \\
\text { Ratio }\end{array}$ & Cycle & Horsepower & Total & $\%$ of Total \\
\hline Waukesha & H 24 GL & Lean Burn & 4 Stroke & 530 & 937 & $19.8 \%$ \\
\hline Caterpillar & G 3408 TA & Rich Burn & 4 Stroke & 400 & 536 & $11.3 \%$ \\
\hline Waukesha & F 18 & Lean Burn & 4 Stroke & 400 & 327 & $6.9 \%$ \\
\hline Caterpillar & G 3516 TALE & Lean Burn & 4 Stroke & 1340 & 323 & $6.8 \%$ \\
\hline Ajax & DPC 280 & Lean Burn & 2 Stroke & 280 & 295 & $6.2 \%$ \\
\hline Waukesha & L 7044 GSI & Rich Burn & 4 Stroke & 1680 & 270 & $5.7 \%$ \\
\hline Ajax & DPC 2802 LE & Lean Burn & 2 Stroke & 316 & 221 & $4.7 \%$ \\
\hline Waukesha & 3524 GSI & Rich Burn & 4 Stroke & 840 & 197 & $4.2 \%$ \\
\hline Waukesha & L 5790 GL & Lean Burn & 4 Stroke & 1215 & 169 & $3.6 \%$ \\
\hline Caterpillar & G 3412 LE & Lean Burn & 4 Stroke & 585 & 142 & $3.0 \%$ \\
\hline Waukesha & VRG 330 & Rich Burn & 4 Stroke & 50 & 104 & $2.2 \%$ \\
\hline Caterpillar & G 3412 TALE & Lean Burn & 4 Stroke & 585 & 99 & $2.1 \%$ \\
\hline Waukesha & L 7042 GSI & Rich Burn & 4 Stroke & $1000-1478$ & 86 & $1.8 \%$ \\
\hline Caterpillar & G 3304 & Rich Burn & 4 Stroke & 80 & 72 & $1.5 \%$ \\
\hline Caterpillar & G 3516 LE & Lean Burn & 4 Stroke & 1340 & 60 & $1.3 \%$ \\
\hline Caterpillar & G 3516 & Lean Burn & 4 Stroke & 1200 & 38 & $0.8 \%$ \\
\hline Superior & 825 & Rich Burn & 4 Stroke & $500-800$ & 35 & $0.7 \%$ \\
\hline Waukesha & L 7042 & Lean Burn & 4 Stroke & 1400 & 35 & $0.7 \%$ \\
\hline Ajax & DPC 360 & Lean Burn & 2 Stroke & 360 & 32 & $0.7 \%$ \\
\hline Ajax & DPC 2803 LE & Lean Burn & 2 Stroke & 600 & 30 & $0.6 \%$ \\
\hline
\end{tabular}


Table 1. Gathering Engines in the DOE Project Database Sorted by Frequency

\begin{tabular}{|c|c|c|c|c|c|c|}
\hline Manufacturer & Model & $\begin{array}{c}\text { Air Fuel } \\
\text { Ratio }\end{array}$ & Cycle & Horsepower & Total & $\%$ of Total \\
\hline Waukesha & L 7042 GL & Lean Burn & 4 Stroke & 1000 & 30 & $0.6 \%$ \\
\hline Ajax & DPC 60 & Lean Burn & 2 Stroke & 60 & 28 & $0.6 \%$ \\
\hline Caterpillar & G 399 TA & Rich Burn & 4 Stroke & $700-900$ & 25 & $0.5 \%$ \\
\hline Ford & LSG 875 & Rich Burn & 4 Stroke & 60 & 25 & $0.5 \%$ \\
\hline Ajax & DPC 140 & Lean Burn & 2 Stroke & 140 & 24 & $0.5 \%$ \\
\hline Caterpillar & G 3512 TALE & Lean Burn & 4 Stroke & 585 & 24 & $0.5 \%$ \\
\hline Caterpillar & G 3306 & Rich Burn & 4 Stroke & 165 & 22 & $0.5 \%$ \\
\hline Caterpillar & G 342 & Rich Burn & 4 Stroke & 185 & 22 & $0.5 \%$ \\
\hline Ajax & DPC 300 & Lean Burn & 2 Stroke & 300 & 21 & $0.4 \%$ \\
\hline Caterpillar & G 3608 TALE & Lean Burn & 4 Stroke & 2222 & 20 & $0.4 \%$ \\
\hline Caterpillar & G 398 & Rich Burn & 4 Stroke & 550 & 20 & $0.4 \%$ \\
\hline Caterpillar & G 398 TA & Rich Burn & 4 Stroke & $450-700$ & 20 & $0.4 \%$ \\
\hline Ajax & DPC 115 & Lean Burn & 2 Stroke & 115 & 18 & $0.4 \%$ \\
\hline Ajax & DPC 180 & Lean Burn & 2 Stroke & 180 & 17 & $0.4 \%$ \\
\hline Ajax & DPC 600 LE & Lean Burn & 2 Stroke & 600 & 17 & $0.4 \%$ \\
\hline Caterpillar & G 3512 & Lean Burn & 4 Stroke & 850 & 16 & $0.3 \%$ \\
\hline Waukesha & L 7042 & Rich Burn & 4 Stroke & 750 & 15 & $0.3 \%$ \\
\hline Caterpillar & G 3306 TA & Rich Burn & 4 Stroke & 165 & 14 & $0.3 \%$ \\
\hline Caterpillar & G 3606 TALE & Lean Burn & 4 Stroke & 1803 & 13 & $0.3 \%$ \\
\hline Clark & RA & Lean Burn & 2 Stroke & $300-500$ & 13 & $0.3 \%$ \\
\hline Ajax & DPC 230 & Lean Burn & 2 Stroke & 230 & 12 & $0.3 \%$ \\
\hline
\end{tabular}


Table 1. Gathering Engines in the DOE Project Database Sorted by Frequency

\begin{tabular}{|c|c|c|c|c|c|c|}
\hline Manufacturer & Model & $\begin{array}{c}\text { Air Fuel } \\
\text { Ratio }\end{array}$ & Cycle & Horsepower & Total & $\%$ of Total \\
\hline Caterpillar & G 3612 & Lean Burn & 4 Stroke & 3335 & 12 & $0.3 \%$ \\
\hline Waukesha & VRG 310 & Rich Burn & 4 Stroke & 50 & 12 & $0.3 \%$ \\
\hline Caterpillar & G 3306 NA & Rich Burn & 4 Stroke & 145 & 11 & $0.2 \%$ \\
\hline Caterpillar & G 3304 NA & Rich Burn & 4 Stroke & 95 & 10 & $0.2 \%$ \\
\hline Caterpillar & G 3412 C LE & Lean Burn & 4 Stroke & 627 & 10 & $0.2 \%$ \\
\hline Ajax & DPC 30 & Lean Burn & 2 Stroke & 30 & 9 & $0.2 \%$ \\
\hline Caterpillar & G 379 & Rich Burn & 4 Stroke & 400 & 9 & $0.2 \%$ \\
\hline Ajax & DPC 360 LE & Lean Burn & 2 Stroke & 360 & 8 & $0.2 \%$ \\
\hline Caterpillar & G 333 & Rich Burn & 4 Stroke & 127 & 8 & $0.2 \%$ \\
\hline Caterpillar & G 3406 TA & Rich Burn & 4 Stroke & 325 & 8 & $0.2 \%$ \\
\hline Caterpillar & G 3412 & & 4 Stroke & 550 & 8 & $0.2 \%$ \\
\hline Caterpillar & G 3412 CLE & Lean Burn & 4 Stroke & 585 & 8 & $0.2 \%$ \\
\hline Clark & HLA8 & Lean Burn & 2 Stroke & 1885 & 6 & $0.1 \%$ \\
\hline Ingersoll-Rand & 412 KVS & Lean Burn & 4 Stroke & 1910 & 6 & $0.1 \%$ \\
\hline Waukesha & F 1197 & Rich Burn & 4 Stroke & $100-300$ & 6 & $0.1 \%$ \\
\hline Caterpillar & G 342 NA & Rich Burn & 4 Stroke & 165 & 5 & $0.1 \%$ \\
\hline Caterpillar & G 3512 LE & Lean Burn & 4 Stroke & 920 & 5 & $0.1 \%$ \\
\hline Caterpillar & G 398 NA & Rich Burn & 4 Stroke & 450 & 5 & $0.1 \%$ \\
\hline Waukesha & F $18 \mathrm{GL}$ & Lean Burn & 4 Stroke & 400 & 5 & $0.1 \%$ \\
\hline Waukesha & L 5790 & Lean Burn & 4 Stroke & $700-1200$ & 5 & $0.1 \%$ \\
\hline Waukesha & L 7042 GU & Rich Burn & 4 Stroke & 800 & 5 & $0.1 \%$ \\
\hline
\end{tabular}


Table 1. Gathering Engines in the DOE Project Database Sorted by Frequency

\begin{tabular}{|c|c|c|c|c|c|c|}
\hline Manufacturer & Model & $\begin{array}{c}\text { Air Fuel } \\
\text { Ratio }\end{array}$ & Cycle & Horsepower & Total & $\%$ of Total \\
\hline Waukesha & LRZB & Rich Burn & 4 Stroke & 330 & 5 & $0.1 \%$ \\
\hline Ajax & DPC 280 LE & Lean Burn & 2 Stroke & 280 & 4 & $0.1 \%$ \\
\hline Ajax & DPC 42 & Lean Burn & 2 Stroke & 42 & 4 & $0.1 \%$ \\
\hline Ajax & DPC 600 & Lean Burn & 2 Stroke & 600 & 4 & $0.1 \%$ \\
\hline Caterpillar & G 3408 TA & Rich Burn & 4 Stroke & 400 & 4 & $0.1 \%$ \\
\hline Caterpillar & G 3408 NA & Rich Burn & 4 Stroke & 255 & 4 & $0.1 \%$ \\
\hline Caterpillar & G 342 TA & Rich Burn & 4 Stroke & 200 & 4 & $0.1 \%$ \\
\hline Caterpillar & G 3606 & Lean Burn & 4 Stroke & 1665 & 4 & $0.1 \%$ \\
\hline Caterpillar & G 3608 & Lean Burn & 4 Stroke & 2222 & 4 & $0.1 \%$ \\
\hline Caterpillar & G 379 TA & Rich Burn & 4 Stroke & $300-400$ & 4 & $0.1 \%$ \\
\hline Cooper & GMVH-10 & Lean Burn & 4 Stroke & 2250 & 4 & $0.1 \%$ \\
\hline Waukesha & 145 & Rich Burn & 4 Stroke & 216 & 4 & $0.1 \%$ \\
\hline Ajax & DPC 140 LE & Lean Burn & 2 Stroke & 140 & 3 & $0.1 \%$ \\
\hline Ajax & DPC 160 & Lean Burn & 2 Stroke & 160 & 3 & $0.1 \%$ \\
\hline Ajax & DPC 2804 LE & Lean Burn & 2 Stroke & 700 & 3 & $0.1 \%$ \\
\hline Ajax & DPC 80 & Lean Burn & 2 Stroke & 80 & 3 & $0.1 \%$ \\
\hline Ajax & DPC 800 & Lean Burn & 2 Stroke & 720 & 3 & $0.1 \%$ \\
\hline Caterpillar & G 3412 TAHCR & Rich Burn & 4 Stroke & 465 & 3 & $0.1 \%$ \\
\hline Caterpillar & G 399 & Rich Burn & 4 Stroke & 665 & 3 & $0.1 \%$ \\
\hline Ford & CSG & Rich Burn & 4 Stroke & 60 & 3 & $0.1 \%$ \\
\hline Ingersoll-Rand & LVG & Rich Burn & 4 Stroke & 485 & 3 & $0.1 \%$ \\
\hline
\end{tabular}


Table 1. Gathering Engines in the DOE Project Database Sorted by Frequency

\begin{tabular}{|c|c|c|c|c|c|c|}
\hline Manufacturer & Model & $\begin{array}{c}\text { Air Fuel } \\
\text { Ratio }\end{array}$ & Cycle & Horsepower & Total & $\%$ of Total \\
\hline Ajax & DPC 800 LE & Lean Burn & 2 Stroke & 650 & 2 & $0.0 \%$ \\
\hline Caterpillar & G 3406 & Rich Burn & 4 Stroke & 280 & 2 & $0.0 \%$ \\
\hline Caterpillar & G 3406 NA & Rich Burn & 4 Stroke & 215 & 2 & $0.0 \%$ \\
\hline Caterpillar & G 3408 & Rich Burn & 4 Stroke & 350 & 2 & $0.0 \%$ \\
\hline Caterpillar & G 3408 LE & Lean Burn & 4 Stroke & 425 & 2 & $0.0 \%$ \\
\hline Caterpillar & G 3508 & & 4 Stroke & 500 & 2 & $0.0 \%$ \\
\hline Caterpillar & G 3508 LE & Lean Burn & 4 Stroke & 515 & 2 & $0.0 \%$ \\
\hline Caterpillar & G 3512 C LE & Lean Burn & 4 Stroke & 945 & 2 & $0.0 \%$ \\
\hline Caterpillar & G 3516 TA & Rich Burn & 4 Stroke & 1085 & 2 & $0.0 \%$ \\
\hline Caterpillar & G 3616 LE & Lean Burn & 4 Stroke & 1340 & 2 & $0.0 \%$ \\
\hline Caterpillar & G 379 NA & Rich Burn & 4 Stroke & 400 & 2 & $0.0 \%$ \\
\hline Caterpillar & G 399 TALCR & Rich Burn & 4 Stroke & 930 & 2 & $0.0 \%$ \\
\hline Generac & 133 GTA & Rich Burn & 4 Stroke & 297 & 2 & $0.0 \%$ \\
\hline Ingersoll-Rand & KVG & Rich Burn & 4 Stroke & 625 & 2 & $0.0 \%$ \\
\hline Superior & 2408 & & & 1600 & 2 & $0.0 \%$ \\
\hline Waukesha & F 135 & Rich Burn & 4 Stroke & 35 & 2 & $0.0 \%$ \\
\hline Waukesha & F 2895 & Rich Burn & 4 Stroke & $600-700$ & 2 & $0.0 \%$ \\
\hline Waukesha & F 817 & Rich Burn & 4 Stroke & $100-350$ & 2 & $0.0 \%$ \\
\hline Waukesha & L 36 GL & Lean Burn & 4 Stroke & 785 & 2 & $0.0 \%$ \\
\hline Waukesha & L 5794 GSI & Rich Burn & 4 Stroke & 1385 & 2 & $0.0 \%$ \\
\hline Ajax & DPC 105 & Lean Burn & 2 Stroke & 105 & 1 & $0.0 \%$ \\
\hline
\end{tabular}


Table 1. Gathering Engines in the DOE Project Database Sorted by Frequency

\begin{tabular}{|c|c|c|c|c|c|c|}
\hline Manufacturer & Model & $\begin{array}{c}\text { Air Fuel } \\
\text { Ratio }\end{array}$ & Cycle & Horsepower & Total & $\%$ of Total \\
\hline Ajax & SB 330 & Lean Burn & 2 Stroke & 330 & 1 & $0.0 \%$ \\
\hline Caterpillar & G 3412 TA & Rich Burn & 4 Stroke & 400 & 1 & $0.0 \%$ \\
\hline Caterpillar & G 342 HAHCR & Rich Burn & 4 Stroke & 225 & 1 & $0.0 \%$ \\
\hline Caterpillar & G 342 TALCR & Rich Burn & 4 Stroke & 265 & 1 & $0.0 \%$ \\
\hline Caterpillar & G 3512 GSI & Rich Burn & 4 Stroke & 520 & 1 & $0.0 \%$ \\
\hline Caterpillar & G 3516 LETA & Lean Burn & 4 Stroke & 1170 & 1 & $0.0 \%$ \\
\hline Caterpillar & G 3516 SITA & Rich Burn & 4 Stroke & 1085 & 1 & $0.0 \%$ \\
\hline Caterpillar & G 3516 TALEHS & Lean Burn & 4 Stroke & 1265 & 1 & $0.0 \%$ \\
\hline Caterpillar & G 3518 LE & Lean Burn & 4 Stroke & 630 & 1 & $0.0 \%$ \\
\hline Caterpillar & G 3606 LE & Lean Burn & 4 Stroke & 1665 & 1 & $0.0 \%$ \\
\hline Caterpillar & G 3606 TA & Rich Burn & 4 Stroke & 1615 & 1 & $0.0 \%$ \\
\hline Caterpillar & G 3616 & Lean Burn & 4 Stroke & 1200 & 1 & $0.0 \%$ \\
\hline Caterpillar & G 3616 TALE & Lean Burn & 4 Stroke & 4705 & 1 & $0.0 \%$ \\
\hline Caterpillar & G 379 TA LCR & Rich Burn & 4 Stroke & 415 & 1 & $0.0 \%$ \\
\hline Caterpillar & G 398 HCTA & Rich Burn & 4 Stroke & 700 & 1 & $0.0 \%$ \\
\hline Clark & HRA8 & Lean Burn & 2 Stroke & 800 & 1 & $0.0 \%$ \\
\hline Cummins & GTA50G2 & & & & 1 & $0.0 \%$ \\
\hline Waukesha & $12 \mathrm{~V}-\mathrm{AT} 27 \mathrm{GL}$ & Rich Burn & 4 Stroke & 3065 & 1 & $0.0 \%$ \\
\hline Waukesha & F 11 GSI & Rich Burn & 4 Stroke & 60 & 1 & $0.0 \%$ \\
\hline Waukesha & L 5108 & Lean Burn & 4 Stroke & 1072 & 1 & $0.0 \%$ \\
\hline Waukesha & L 5108 GL & Lean Burn & 4 Stroke & 1122 & 1 & $0.0 \%$ \\
\hline
\end{tabular}


Table 1. Gathering Engines in the DOE Project Database Sorted by Frequency

\begin{tabular}{|l|l|l|l|r|r|r|}
\hline Manufacturer & \multicolumn{1}{l|}{ Model } & \multicolumn{1}{c|}{$\begin{array}{c}\text { Air Fuel } \\
\text { Ratio }\end{array}$} & \multicolumn{1}{c|}{ Cycle } & Horsepower & Total & \% of Total \\
\hline Waukesha & L $5108 \mathrm{GU}$ & Rich Burn & 4 Stroke & 600 & 1 & $0.0 \%$ \\
\hline Waukesha & L $5790 \mathrm{GU}$ & Rich Burn & 4 Stroke & 877 & 1 & $0.0 \%$ \\
\hline Waukesha & L 5794 & Lean Burn & 4 Stroke & 1250 & 1 & $0.0 \%$ \\
\hline Waukesha & L 5794 LT & Lean Burn & 4 Stroke & 1354 & 1 & $0.0 \%$ \\
\hline Waukesha & L 7042 GNA & Rich Burn & 4 Stroke & 896 & 1 & $0.0 \%$ \\
\hline Waukesha & VRG 22O & Rich Burn & 4 Stroke & 42 & 1 & $0.0 \%$ \\
\hline TOTAL & & & & & $\mathbf{4 7 2 9}$ & $\mathbf{1 0 0 . 0 \%}$ \\
\hline
\end{tabular}

\begin{tabular}{|c|c|}
\hline \multicolumn{1}{|c|}{ Table 2. Source of Engine Information } \\
\hline Database & Number of Engines \\
\hline $\begin{array}{c}\text { State of Wyoming Engine Inventory } \\
\text { Database }\end{array}$ & 3,372 \\
\hline $\begin{array}{c}\text { GTI/PRCI Engine and Turbine Database } \\
\text { (Gathering Engines Only) }\end{array}$ \\
\hline $\begin{array}{c}\text { Database of Colorado and New Mexico Engines } \\
\text { from Universal Compression }\end{array}$ \\
\hline $\begin{array}{c}\text { Survey of Engines at Stations with Newly } \\
\text { Permitted Units in Nine Western States }\end{array}$ \\
\hline
\end{tabular}




\title{
Task 3: Identify and assess commercial and emerging control and monitoring technologies
}

With a comprehensive review of emissions issues, technology trends and existing commercial offering, the appropriate technologies can be identified for application as suitable retrofits for the fleet of gas engines in natural gas exploration and production (E\&P) applications.

Characterizing technologies include understanding the underlying science of each option, the overall costs to retrofit the technology and associated equipment, recurring maintenance costs to operate in compliance, any incremental fuel costs, and emissions monitoring requirements (and expenses). Energy and Environmental Analysis, Inc. (EEA) is responsible for the Technology Characterization task of the overall Emissions Controls for E\&P Engines project. To that end, EEA has been pursuing an approach that includes:

- Describing baseline information on emissions of gas engines

- Identifying applicable retrofit technologies for the class of engines to be addressed

- Gathering technical, operational, and economic information on available technologies and ancillary equipment

- Analyzing technologies based on cost effectiveness and applicability to E\&P fleet of engines

This report summarizes work done form July 2003 through September 2003. It includes summary information on providers of commercially available retrofit products for emissions controls for gas engines and their suitability for the E\&P engines. This dovetails the work contained in the June 2003 status report in which approaches to reducing emissions and current research and development were presented. Presented in this status report is a summary of options offered by original equipment manufacturers (OEM's) and aftermarket providers. This report also provides a short summary of Homogeneous Charge Compression Ignition (HCCI) technology. HCCI is a long term development approach well beyond the time frame for testing and demonstration under this program that is currently being pursued in the transportation sector and may eventually be applied in stationary application.

\section{Providers of Retrofit Controls}

EEA reviewed product offerings from LEC retrofit providers of retrofit options and developed the summary profiles at the end of this report. These include the following:

\author{
OEMS \\ Caterpillar \\ Cooper AJAX \\ Waukesha
}

\section{Aftermarket Providers \\ Altronic \\ Continental Controls}




\author{
DigiCon \\ Enginuity \\ Hoerbiger \\ REM Technology
}

Cost analysis of the various commercial options will be assessed in a following status report.

\title{
Low Emission Combustion Retrofits
}

As discussed in the June 2003 status report, lean burn engines and retrofit combustion approaches to lower emissions will be reviewed. Other technologies such as Non-Selective Catalytic Reduction (NSCR) and Pre-Stratified Charge (PSC) are the much more common approaches on rich-burn engines. These were summarized in the June status report.

Low emission combustion (LEC) in engines typically involves modifying the mechanical and control designs of the combustion system to achieve very lean combustion compared to the air/fuel ratios of what are considered conventional lean-burn engines. Controls, air/fuel mixing, and sensors are key enabling technologies.

To deliver the additional combustion air required for LEC, turbocharging and intercooling normally are required. For retrofits, this usually involves upgrading or replacing existing turbochargers and intercoolers or adding equipment that is not already present. This is the case with naturally aspirated engines. While turbocharging and intercooling are primarily used to enhance engine performance, they are integral to LEC for most engines. Other equipment associated with increased air flows may also need to be modified. They include air/fuel ratio control, air intake and filtration system, intercooler radiator and exhaust and noise suppression equipment.

These modifications and additional equipment, while economically reasonable for large engine systems, represent high specific costs $(\$ / \mathrm{bhp})$ on lower horsepower equipment.

\section{Challenges}

The challenge with lean combustion is to simultaneously achieve proper ignition and stable combustion. Developers and providers of technology have net these requirements with some combination of improved combustion chamber design, enhanced air-fuel mixing, and improved ignition systems.

In many cases a pre-combustion chamber is used to enhance ignition. In this system, ignition is initiated in a small chamber with a fuel0rich environment. The flame then propagates rapidly and forcefully from the pre-chamber into the main combustion chamber, providing uniform ignition of the very lean air-fuel mixture in the main chamber as well as improved mixing.

Some engine manufacturers offer their smaller engines with open chamber LEC systems. These engines feature a redesigned combustion chamber rather than a pre-combustion chamber. The open chamber LEC design reply on improved air-fuel mixing designs to achieve stable combustion at lean conditions. Engines with open-chamber technology are 
designed for excess air levels only slightly above $50 \%$, while pre-chamber systems are designed for excess air levels of $75 \%$ to over $100 \%$. Consequently, pre-chamber engines have generally lower $\mathrm{NO}_{\mathrm{x}}$ emissions than open chamber engines.

\section{OEM's}

LEC with pre-combustion chamber technology has been in use for about 20 years, since Cooper-Bessemer began manufacturing their CleanBurn engines. Other engine manufacturers followed suit and began to manufacture LEC-equipped engines (both pre-chamber and open chamber). All major OEM's currently offer LEC-equipped models. Many models are only available with LEC. Some OEM's offer models available in either rich-burn or LEC.

Shortly after offering new LEC-equipped engines, OEM's began to offer retrofit kits and installation services on existing engines. The retrofits involved completely replacing the cylinder heads with redesigned heads and replacing or modifying numerous components. The retrofit cylinder heads are cast with a pre-combustion chamber within the interior of the head. As one would expect, these retrofits involve relatively high costs. Costs could be reduced if the retrofit is done when cylinder heads and/or other components are to be replaced as part of an overhaul.

\section{Aftermarket Providers}

Due to the high costs of the original OEM-offered retrofits, simpler less expensive LEC retrofit kits have been developed. The development of screw-in combustion pre-chambers has been one of the cost cutting technologies widely implemented. These pre-combustion chambers screw into existing spark plug hole in each cylinder head, elimination the need to replace the existing cylinder heads. The screw-in pre-chambers are now offered by both third party vendors and OEM's. In addition, other advances have been made to reduce costs. Upgrades to existing turbocharging systems without replacement are sometimes possible. Retrofit providers also offer systems that involve innovative approaches to improve air-fuel mixing. These include fuel valves that allow for high pressure and supersonic fuel injection.

\section{Application}

LEC technology is applicable to engines fired with gaseous fuels. Retrofit equipment and installation services are generally available for the most popular engine models. Cooper Energy Services (CES), maker of Cooper-Bessemer, Ajax, Superior, and Delaval, provides retrofits for all its larger models and offers services for engines manufactured by other companies as well. Waukesha Engine of Dresser Industries manufacturers two engine families that are either rich-burn or LEC configurations. The company offers LEC retrofit for engines originally configured as rich-burn. Caterpillar also offers retrofit services for its most popular lines. Third party suppliers such as Altronic, Continental Controls, DigiCon, Enginuity, Hoerbiger, and REM Technology, offer retrofit services and are demonstrating potential lower cost options for engine models not currently supported by OEM's.

Information on LEC performance was reviewed. Information from engine OEM's that provide retrofit equipment and services indicates guaranteed levels in the range of 1.5 to 3.0 
$\mathrm{g} / \mathrm{bhp}$-hr. It was pointed out that these guarantees reflect the performance of "standard" kits that have been developed by OEM's. Retrofit kits can be tailored to meet a target emissions level, although the costs may be greater than the standard kit.

Third party retrofit providers typically look to address anything but standard needs. Some have guaranteed emissions as low as $1.0 \mathrm{~g} / \mathrm{bhp}-\mathrm{hr}^{1}$. However many retrofit solutions are designed to achieve the applicable emissions limit (usually 2.0 to $6.0 \mathrm{~g} / \mathrm{bhp}$-hr) on a sitespecific basis and involve solutions that take into consideration state of equipment and customer limits on costs to achieve emissions target.

It should be noted that OEM's have the capability to reduce $\mathrm{NO}_{\mathrm{x}}$ emissions to lower levels on engines that third party vendors find problematic. For example, OEM's are able to replace engine parts, such as cylinder heads, with redesigned parts to overcome the impediments to low emissions. However these redesigned parts often come at a higher price.

Information reviewed does not suggest any notable difference in NOx guarantee based on operating cycle.

\section{Long-Term Test Data}

A 1998 paper $^{2}$ examined long-term test data for several engine models equipped with LEC technology. One of the engines tested has relevancy to E\&P applications, $180 \mathrm{hp} \mathrm{2-stroke}$ Ajax DPC-180. Sixty-eight individual tests were conducted on four different engines fired with natural gas between 1982 and 1996. The engines averaged $\mathrm{NO}_{\mathrm{x}}$ emissions of $0.6 \mathrm{~g} / \mathrm{bhp}$ $\mathrm{hr}$ with a high of $1.1 \mathrm{~g} / \mathrm{bhp}$-hr. Product literature from Cooper Energy Services states the guaranteed emissions on new Ajax units with pre-chamber (LE) configurations to be 2.0 $\mathrm{g} / \mathrm{bhp}-\mathrm{hr}$. The primary application for Ajax integral units (range from 100-800 hp) is natural gas compression.

\section{Cost Issues}

The costs of $\mathrm{NO}_{\mathrm{x}}$ controls vary widely depending on the individual site, size of engine, type of engine, operational characteristics of engine, and other parameters. For engines requiring the installation of major equipment components such as engine cylinder heads and turbochargers, the largest expense is the capital cost of controls. Other expenses that should not be overlooked include such things as engineering labor, construction project management, testing, permitting, etc. Site-specific concerns include safety issues, limited room for turbocharger, unusual permit conditions, unmanned operation, construction schedules, warranty requirements, special acceptance testing, etc. All these factor point to the need for good, well-defined specification in the agreement between customer and retrofit provider.

It is generally accepted that OEM retrofits are significantly higher than third party providers. The conventional OEM retrofit has high costs because they involve a nearly complete makeover of the engine. This involves replacement of many engine components in addition to the cylinder heads (e.g., cylinder sleeves, pistons, exhaust manifold, etc.). While costs from

\footnotetext{
${ }^{1}$ Edgerton, Lee-Grec, Walsh for EPA Ozone Policy and Standards Group, September 2000

${ }^{2}$ Ventura County Air Pollution Control District, 1998
} 
OEM's have come down slightly due pressure from third parties they can still be as much as $50-150 \%$ higher. Low installation costs can be achieved when all the right conditions exist. For example, a customer may have an existing turbocharger with adequate capacity and elected to use screw-in pre-combustion chambers.

Third party providers note that it is difficult to conduct "apples to apples" comparisons on costs, as the cost of a retrofit is very dependent on the particular engine being serviced. Many engines have been upgraded and modernized over time with such improvements as electronic ignition systems. Some engines have not and consequently require these improvements at the time of retrofit. In some rare cases, atypical construction coasts may be incurred.

\section{Homogeneous Charge Compression Ignition ( $\mathrm{HCCl})$}

$\mathrm{HCCI}$ is an alternative piston engine combustion process that can provide efficiencies as compression-ignition direct ignition engines (CIDI), commonly known as diesel cycle engines, with very low $\mathrm{NO}_{\mathrm{x}}$ and particulate emissions. HCCI engines operate on the principle of having a dilute, premixed charge that reacts and burns volumetrically throughout the cylinder as it is compressed by the piston. It is said to incorporate the best features of both spark ignition and compression ignition engines. As in an SI engine, the charge is well mixed which minimized particulate emissions. As in a CIDI engine, the charge is compression ignited and has no throttling losses, which leads to high efficiency. But unlike either conventional engine, combustion occurs simultaneously throughout the volume rather than in a flame front. This important attribute of HCCI allows combustion to occur at lower temperatures and consequently dramatically reducing $\mathrm{NO}_{\mathrm{x}}$.

HCCI is shown schematically and contrasted with traditional SI and CIDI engines in Figure 1.

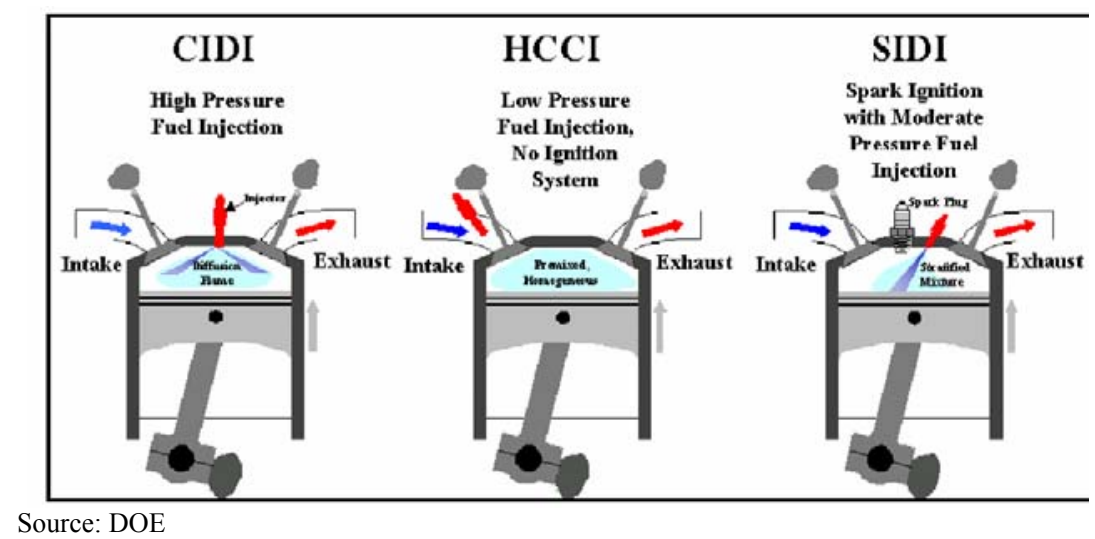

Figure 1: HCCI

HCCI, as most-typically envisioned, would use low pressure fuel injection outside the cylinder and no ignition system. If a charge is desired, it may be necessary to use in-cylinder injection. 
HCCI combustion is achieved by controlling the temperature, pressure, and composition of the air/fuel mixture. This control system is fundamentally more challenging than SI and CIDI engines. Electronic controls have enabled consideration of HCCI for application to commercial engines. Japan, USA, and European countries have aggressive HCCI R\&D programs. HCCI R\&D is targeting primarily vehicle applications, but is also applicable to reciprocating engines used for electric power generation and compressor drive.

HCCI is still very much in the midst of a long-term R\&D and while benefits are promising, commercial application is not likely in the timeframe of this project.

\section{Further Work Planned}

During the next quarter, the research team will direct most of its effort on Task 2, which will lay the groundwork for Tasks 3 and 4. Upon completion of Task 2, the research team will shift their effort to the identification of control technologies and market gaps.

\section{Task 2: Develop a Database of Existing E\&P Engine Inventory}

During the next reporting period, Coerr Environmental will continue to add new engines to the database, perform QA/QC checks on the existing database, sort the engines by geographical location, present information on current emission limits typically applied to this engine population, and develop additional analysis of the engine types in natural gas gathering.

\section{Task 3: Assess Control and Monitoring Technologies}

Summarize the existing technologies, and describe emerging technologies.

\section{Task 4: Determine Technology and Market Gaps}

This task will use the emissions control approaches identified in Task 3.0 to determine the practical targets for the magnitude of emissions reduction in E\&P engines. Once the reduction magnitudes are determined, each will be ranked by how applicable it is to the specific inventory of field engines, its expected cost of implementation, and the overall emissions reduction that can be reasonably anticipated from further development and commercialization of the technology.

The second portion of this task will compare the expected emissions reduction performance to the current and expected emissions permitting requirements facing the E\&P industry. Doing so will identify the high-impact control technologies that are expected to be widely utilized by the E\&P industry, and which should be targeted either for immediate testing, or require more fundamental component development.

This work will be performed during the third quarter of 2003, in parallel with Task 3 , and during the fourth quarter of 2003. It is expected that work will center on three major areas: 1) engine controls; 2) ignition systems; and 3) exhaust gas treatment options

\section{Task 5: Conduct Controlled Tests to Evaluate Promising Technologies}

The most promising technologies identified in Tasks 3 and 4 will be tested under controlled conditions on an Ajax engine, which is in very wide use in E\&P operations. The tests will most undoubtedly be conducted at Ricardo, Inc. in Burr Ridge, IL. Ricardo operates a set of state-of-the-art, fully instrumented test cells that can accommodate engines up to 1,000 HP. 
Up to 160 hours of test time at Ricardo are planned to conduct preliminary performance testing of the array of promising technologies identified in Task 3.

Assuming that an engine can be located, the tests will be conducted during the first quarter of 2004.

\section{Task 6: Determine on-engine control system and sensor requirements for remote emissions monitoring}

This task will identify the necessary sensors, software, and hardware to provide remote engine emissions and performance monitoring. The results from Task 3.1 will be used to determine the scope and content of a monitoring system. The project team has expertise in this area, and has actually developed and implemented remote sensing technologies for pipeline engines for what is arguably the most stringent real-time emissions monitoring program in the world (California's RECLAIM program).

\section{Conclusions}

The primary conclusion drawn from the work that was completed during the second quarter is that several promising technologies were identified that are candidates for E\&P engines.

These technologies include control and monitoring technologies and in most cases can be used to monitor engine performance as well as control and monitor engine emissions. The key four stroke engine models are the Waukesha and Caterpillar engines, while the key two-stroke cycle engine model is the Ajax engine. 